\title{
Effect Of Short Term Aerobic Exercise (Football Training) On Lipid Profile And Myoglobin Levels In Apparently Healthy Students Of College Of Health Sciences, Nnamdi Azikiwe University, Nnewi Campus, Anambra State, Nigeria.
}

\author{
*Ezeugwunne Ifeoma Priscilla ${ }^{2,3}$, Chukwu Goodness Nkechinyere ${ }^{2}$, Ogbodo Emmanuel \\ Chukwuemeka $^{2}$, Analike Rosemary Adamma ${ }^{1}$, Onyegbule Onyema Athanatius ${ }^{1}$, Oguaka Victor \\ Nwabunwanne $^{3}$, Mbaeri Timothy Uzoma ${ }^{4}$, Amah Akuma Kalu ${ }^{5}$, Meludu Samuel Chukwuemeka ${ }^{2,3}$. \\ ${ }^{1}$ Department of Chemical Pathology, Faculty of Medicine, Nnamdi Azikiwe University, Nnewi Campus; \\ ${ }^{2}$ Department of Medical Laboratory Science, Faculty of Health Sciences, Nnamdi Azikiwe University, \\ Nnewi Campus; \\ ${ }^{3}$ Department of Human Biochemistry, Faculty of Basic Medical Sciences, Nnamdi Azikiwe University, \\ Nnewi Campus; \\ ${ }^{4}$ Department of Surgery, Faculty of Medicine, Nnamdi Azikiwe University, Nnewi Campus, Anambra State Nigeria; \\ ${ }^{5}$ Department of Physiology, College of Medicine, Imo State University, Owerri. \\ *Corresponding author: Dr. Ezeugwunne Ifeoma Priscilla ${ }^{1,2}$
}

\begin{abstract}
This study investigated the effect of short term aerobic exercise on lipid profile and myoglobin levels in apparently healthy students of College of Health Sciences, Nnamdi Azikiwe University, Nnewi Campus, Anambra State, Nigeria. A total of 60 apparently healthy young students aged between 18-40 years were randomly selected for the study. They were rested for a period of two weeks after which they were subjected to football exercise for 30 minutes ( 3 times) in a week for a period of 3 weeks. The demographic and anthropometric data of subjects were obtained using a well-structured questionnaire. Their blood pressures reading were obtained also. Thereafter, $5 \mathrm{mls}$ of baseline (day 0) and post-exercise (day 21) blood samples were collected from each subject before the commencement and at the end of the exercise on the last day of the training into a plain container for estimation of biochemical parameters (TG, TC, LDL, HDL, Myoglobin levels) respectively using standard methods. Data obtained were statistically analysed by unpaired student t-test and Pearson $\mathrm{r}$ correlation. The result showed that the mean serum levels of TG $(1.41 \pm 0.60$ vs $1.04 \pm 0.43)$ TC $(5.22 \pm 0.98$ vs $4.41 \pm 0.90)$, LDL $(3.92 \pm 0.99$ vs $3.36 \pm 0.92)$ as well as myoglobin $(16.04 \pm 4.64$ vs $13.38 \pm 5.21)$ and DBP $(75.16 \pm 10.54$ vs $68.59 \pm 8.57)$ were significantly decreased, whereas, there was a significant increase in the mean serum level of HDL $(0.83 \pm 0.30$ vs $0.95 \pm 0.28)$ and SBP $(114.69 \pm 9.21$ vs $131.48 \pm 12.84)$ in subjects after exercise when compared to before exercise $(\mathrm{p}<0.05)$. However, the mean BMI of the subjects remained the same before and after exercise $(p>0.05)$. Therefore, short term moderate intensity aerobic exercise could be of importance in prevention and management of cardiovascular disease.
\end{abstract}

Key Words: Short Term Aerobic Exercise, Football Training, Lipid Profile, Myoglobin, Apparently Healthy Students, Nnewi Campus.

\section{Introduction}

The word exercise is derived from the latin word "EXERCITIUM" which means to train. Exercise is a process in which energy stored as chemical compound is transformed into mechanical and heat energy (Nevell et al., 1989). Exercises are generally grouped into three types depending on the overall effect they have on the human body: 
1. Aerobic exercises; such as cycling, walking, running, hiking and playing tennis, football, volleyball, jogging, etc; focus on increasing cardiovascular endurance (Wilmore and Knuttgen, 2003).

2. Anerobic exercises; such as weight training, increase short term muscle strength (De vos et al., 2005).

3. Flexibility exercises; such as stretching, improve the range of motion of muscles and joints $\left(\mathrm{O}^{\prime}\right.$ Connor et al., 2006).

Aerobic exercise is physical exercise of relatively low intensity that primarily depending on the aerobic energy-generating process (Plowman and Smith, 2007). Aerobic denotes "with oxygen" referring to the use of oxygen in order to adequately meet energy demands during exercise through aerobic metabolism (McArdle et al., 2006). Physical exercise has become increasingly popular as a method of health enhancement. Epidemiologic and laboratory studies have shown that increased levels of physical activity are associated with longevity and reduced risk for cardiovascular disease (Benedict et al., 1996; Blair and Morris, 2009; Charkoudian et al., 2006).Lack of activity, on the other hand, has been shown to be associated with decreased exercise capacity, cardiovascular deconditioning, and muscule atrophy (Davy et al., 1996; DeSouza et al., 2000).Regular physical activity is an essential component of a healthy lifestyle that helps to keep fitness of the body (Jourkesh et al., 2011). Probably because of heavy academic demands of medical college, most of medical students lead a physically inactive life. It may cause medical students exhausted or may have no time to exercise (Choudhary et al., 2015). The American College of Cardiology/American Heart Association recommends at least 30 minutes of moderate (at 50-70\% of maximal predicted heart rate) exercise on most days to reduce the risk of cardiovascular events (NCEP, 2002). Several human studies clearly demonstrate that chronic aerobic exercise regimens improve cardiovascular function. This is true not only in healthy subjects without any underlying risk factors (Clarkson et al., 1999), but also in older people (Benjamin et al., 2004), and those with cardiovascular risk factors (Hambrecht et al., 1998). Indeed, those with cardiovascular risk factor/disease will benefit more. There is a much higher consistency in the results of studies which assess participants with cardiovascular disease/risk factors compared to healthy subjects. Patients with hypertension (Higashi et al., 1999), type 2 diabetes (O'Keefe et al., 2010), metabolic syndrome (Blair, 2009), stable cardiovascular disease (Penedo and Dahn, 2005), myocardial infarction (Durstinea et al., 2013), all benefit from exercise training compared to those who do not participate in any training. Importantly, an exercise regimen that improves endothelial function in diabetic patients fails to benefit healthy subjects (Maiorana et al., 2001). In healthy individuals, a longer and more intense exercise protocol is needed to induce measureable changes in cardiovascular parameters, while older and sicker subjects can benefit from less intense exercise regimens. Treatment and control of established known cardiovascular risk factors includes the reduction of hypercholesterolemia, hypertension, and smoking (Lavrenčič et al., 2000). Physical activity, as one the most important components of cardiovascular disease prevention, has crucial roles at all levels. Despite the strong evidence linking physical activity to cardiovascular disease risk reduction, there remains much uncertainty regarding the underlying mechanisms. Scientific and technological advances have almost completely eliminated the necessity for physical exertion in daily life that has been especially true in the past few generations (O'Keefe et al., 2010). On the other hand athletes lead a physically active life as their academic curriculum itself includes daily physical exercise and outdoor games (Choudhary et al., 2015). It has been documented physical inactivity as a major health problem(Blair, 2009) and regular exercise is important for health and well being(Wilt et al., 2004; Hollmann et al., 2007; Sattelmair et al., 2009). Physical inactivity is contributing factor in several chronic diseases and conditions (Vona et al., 2004; Hambrecht et al., 2000). Physiology of Exercise offers the student an opportunity to observe the effect of training and helps to evaluate the Cardiovascular system. This has created a great enthusiasm in our mind to undergo this study. Therefore, this study is designed to assess the effects of exercise (football practice) on the lipid and myoglobin level of healthy subjects of College of Health Sciences, Nnamdi Azikiwe University, Nnewi Campus, Anambra State, Nigeria. Findings from this study may hopefully provide further evidence that will guide the use of physical exercise to improve the health of both apparently healthy as well as sick individuals in our community and the world at large. 


\section{Materials And Methods \\ Study Area}

The study was carried out in College of Health Sciences, Nnamdi Azikiwe University, Nnewi Campus, Anambra State, Nigeria.

\section{Experimental Design}

A total of sixty (60) students (secondary/amateur football players) who volunteered to participate in the study, were recruited for this study. The subjects were instructed not to participate in any form of sports for one-week. After the one week of rest, the subjects were randomly selected. Each team was then subjected to football training for a minimum time of (30mins) for three consecutive days in one-week.

A pre-exercise blood pressure(BP) was measured by taking two BP readings on the right arm placed at the heart level, using an automatic blood pressure measuring device OMRON 907 (OMRON, Hoofdorrp, Netherlands) after the subjects had rested for at least 5minutes in a sitting position upon arrival to the football court. The measurements were taken 60 seconds apart and the average pre and post blood pressures were recorded and used for our analyses.After the blood pressures were taken, 5mls of preexercise(baseline) blood sample was drawn from the ante-cubital vein of each of the participating subject before the commencement of the exercise (day zero). Post-exercise blood sample and blood pressure were also taken after exercise on the last day (day 21). Anthropometric parameters such as the height and weight of each subject were measured using a standard standiometer and a weighing scale before the exercising session and their body mass index (BMI) were calculated from it. Subjects' dietary pattern and lifestyle were also obtained using a well-structured questionnaire. Thereafter, the biochemical parameters (LDL, HDL, TG, TC, and Myoglobin levels) were subjected to laboratory analysis. LDL level was determined using enzymatic method as described by Assman et al. (1984); HDL level was determined using enzymatic method as described by Burstein et al. (1980). The enzymatic method as described by Tietz (1990) was adopted in the estimation of serum triglycerides, whereas, total cholesterol level was determined using the enzymatic method as described by Roeschlau et al. (1974). Myoglobin level was assayed using the method as described by Saranchak and Bernstein, (1974). The blood pressure readings were determined using the method described by Chobanian et al., (2003).

\section{Ethical Consideration}

Ethical approval was sought and obtained from the Ethics Committee of Nnamdi Azikiwe University Teaching Hospital, Nnewi, Anambra State, Nigeria in accordance with the declaration of Helsinki on research involving human subjects (Snezana, 2001; Levine and Robert, 2006). Inclusion and Exclusion

\section{Criteria}

Apparently healthy students' age between $(18-40)$ years, which were willing to participate in the study were included for the study whereas, the subjects younger or older than 40 years old; those suffering from cardiovascular diseases or who sustained any form of musculo-skeletal injury, alcoholics and smokers were excluded from the study.

\section{Statistical Analysis}

Statistical package for social science (SPSS) version 20 was employed in the analysis of the result and the data obtained for cardiovascular function parameters were expressed as mean \pm standard deviation and parameters were compared using unpaired student t-test and Pearson $r$ correlation. Level of significance was set at $\mathrm{P}<0.05$.

\section{Results}

The mean values of their age, weight, height and BMI were $(23.69 \pm 3.29 \mathrm{yrs}, 63.14 \pm 9.89 \mathrm{Kg}, 1.68 \pm 0.78 \mathrm{~m}$, $22.41 \pm 2.22 \mathrm{Kg} / \mathrm{m}^{2}$ ) respectively for both pre and post exercise. Their mean diastolic blood pressure was significantly reduced after exercise $(\mathrm{P}<0.05)$. However, the mean pre and post exercise systolic blood pressure showed significant increase after exercise (Pre-114.69 $\pm 9.21 \mathrm{mmHg}$; Post-131.48 $\pm 12.84 \mathrm{mmHg}$; $\mathrm{P}<0.05)$, See table 1. 
Table 1: Anthropometric measures of participants (Mean $\pm \mathrm{SD}, \mathrm{N}=60$ ).

\begin{tabular}{|c|c|c|c|c|c|c|}
\hline Group & Age & Weight & Height & BMI & SBP & DBP \\
\hline $\begin{array}{l}\text { Pre- exercise } \\
n=60\end{array}$ & $23.69 \pm 3.29$ & $63.14 \pm 6.89$ & $1.68 \pm 0.78$ & $22.41 \pm 2.22$ & $114.69 \pm 9.21$ & $75.16 \pm 10.54$ \\
\hline Post exercise $n=60$ & $23.69 \pm 3.29$ & $63.14 \pm 6.89$ & $1.68 \pm 0.78$ & $22.41 \pm 2.22$ & $131.48 \pm 12.84$ & $68.59 \pm 8.57$ \\
\hline t-value & 0.000 & 0.000 & 0.000 & 0.000 & 1.826 & 4.999 \\
\hline p-value & $>0.05$ & $>0.05$ & $>0.05$ & $>0.05$ & $<0.05$ & $<0.05$ \\
\hline
\end{tabular}

*Statistically significant at $\mathbf{p}<0.05$.

There were significant decrease in the mean values of triglycerides, total cholesterol, low density lipoprotein and myoglobin levels in the subjects post-exercise compared with pre-exercise levels $(\mathrm{p}<0.05)$. There was however, a significant increase in the mean values of the participant HDL level after exercise $(\mathrm{P}<0.05)$, see table 2 .

Table 2: The mean serum values of lipid profile and myoglobin levels of the subjects before and after exercise.

\begin{tabular}{|c|c|c|c|c|c|}
\hline Group & TG & TC & HDL & LDL & MYOGLOBIN \\
\hline $\begin{array}{l}\text { Pre- exercise } \\
n=60\end{array}$ & $1.41 \pm 0.60$ & $5.22 \pm 0.98$ & $0.83 \pm 0.30$ & $3.92 \pm 0.99$ & $16.04 \pm 4.64$ \\
\hline Post- exercise $n=60$ & $1.04 \pm 0.43$ & $4.41 \pm 0.90$ & $0.95 \pm 0.28$ & $3.36 \pm 0.92$ & $13.38 \pm 5.21$ \\
\hline t- value & 8.525 & 1.212 & 0.925 & 0.381 & 1.359 \\
\hline p- value & 0.000 & 0.000 & 0.019 & 0.001 & 0.003 \\
\hline
\end{tabular}

*Statistically significant at $\mathbf{p}<0.05$.

Interestingly, there was no significant correlations observed in the parameters studied in the subjects before and after exercise ( $p>0.05)$, see table 3 and 4 respectively. 
Table 3: Levels of association between parameters studied in pre-exercise subjects

\begin{tabular}{|c|c|c|c|c|}
\hline Parameter & $\begin{array}{l}\text { Pearson's } \\
\text { coefficient }\end{array}$ & correlation & f-values & p-value \\
\hline TG vs HDL & -0.021 & & 0.815 & $>0.05$ \\
\hline TG vs BMI & -0.048 & & 0.587 & $>0.05$ \\
\hline TG vs Age & 0.037 & & 0.675 & $>0.05$ \\
\hline TC vs weight & 0.009 & & 0.920 & $>0.05$ \\
\hline HDL vs Myoglobin & 0.034 & & 0.704 & $>0.05$ \\
\hline HDL vs BMI & -0.025 & & 0.779 & $>0.05$ \\
\hline HDL vs SBP & -0.037 & & 0.679 & $>0.05$ \\
\hline HDL vs Age & 0.035 & & 0.694 & $>0.05$ \\
\hline LDL vs weight & 0.021 & & 0.818 & $>0.05$ \\
\hline Myoglobin vs weight & 0.002 & & 0.986 & $>0.05$ \\
\hline Myoglobin v DBP & -0.027 & & 0.762 & $>0.05$ \\
\hline Height v SBP & 0.000 & & 0.999 & $>0.05$ \\
\hline
\end{tabular}

*Statistically significant at $\mathbf{p}<0.05$.

Table 4: Levels of association between parameters studied in post-exercise subjects

\begin{tabular}{|c|c|c|c|}
\hline Parameters & $\begin{array}{l}\text { Pearson's } \\
\text { coefficient }\end{array}$ & correlation f-values & p-value \\
\hline TG vs TC & 0.029 & 0.818 & $>0.05$ \\
\hline Weight vs HDL & -0.013 & 0.981 & $>0.05$ \\
\hline Weight vs SBP & 0.010 & 0.940 & $>0.05$ \\
\hline TC vs weight & 0.003 & 0.981 & $>0.05$ \\
\hline HDL vs Weight & -0.013 & 0.918 & $>0.05$ \\
\hline HDL vs Age & -0.037 & 0.770 & $>0.05$ \\
\hline BMI vs SBP & 0.037 & 0.773 & $>0.05$ \\
\hline Weight vs TC & 0.003 & 0.980 & $>0.05$ \\
\hline Weight vs DBP & -0.035 & 0.784 & $>0.05$ \\
\hline Myoglobin vs weight & -0.025 & 0.841 & $>0.05$ \\
\hline Myoglobin vs DBP & -0.003 & 0.980 & $>0.05$ \\
\hline Height vs SBP & 0.037 & 0.769 & $>0.05$ \\
\hline
\end{tabular}

*Statistically significant at $\mathbf{p}<\mathbf{0 . 0 5}$. 


\section{Discussion}

Several reports have shown that duration and/ or intensity of exercise elicit different effects on minerals metabolism and that inadequate status of the body mineral composition can lead to a diminution of performance and endurance both in sportsmen and rats (McDonald and Keen, 1988; Rassiguier et al., 1990; Clarkson, 1991). Other report showed clearly during aerobic exercise, systolic BP increases as the exercise intensity increases the heart works harder to pump more oxygenated blood to the muscles (Meludu et al., 2002). At the same time, diastolic BP remains relatively stable and may even decrease slightly. On average, men have higher BP than women during aerobic exercise (Brooks et al., 2005).

From this study, it was observed that the mean values of the subjects' age, weight, height and BMI were $\left(23.69 \pm 3.29 \mathrm{yrs}, 63.14 \pm 9.89 \mathrm{Kg}, 1.68 \pm 0.78 \mathrm{~m}, 22.41 \pm 2.22 \mathrm{Kg} / \mathrm{m}^{2}\right)$ respectively for both pre and post exercise. It was also observed that diastolic blood pressure was significantly reduced after exercise (Pre$75.16 \pm 10.54 \mathrm{mmHg}$; Post $-68.59 \pm 8.57 \mathrm{mmHg})(\mathrm{P}<0.05)$ but there was an increase change in systolic blood pressure after exercise (Pre-114.69 $\pm 9.21 \mathrm{mmHg}$; Post-131.48 $\pm 12.84 \mathrm{mmHg}$ ). The findings from this work revealed that during short-term football exercise, diastolic pressure decreased significantly. This decrease in the diastolic pressure can be attributed primarily to the vasodilation of the arteries from the exercise bout which causes a reduction in peripheral resistance. It could also be due to a decrease in the blood volume caused by dehydration which causes water loss after exercise. This finding is in consonance with the findings of Kelly, (2000) who conducted a meta-analysis on resistance exercise and reported a decrease in diastolic blood pressure. However, there was also a significant increase in their systolic blood pressure. A negative correlation between the systolic and diastolic blood pressure after the exercise was observed, whereas the pre-exercise blood pressure showed a positive correlation, showing that the change was exercise induced. There was a significant decrease in the mean values of triglycerides, total cholesterol, low density lipoprotein and myoglobin $(\mathrm{p}<0.05)$, this decrease in the values of triglyceride may be attributed to low fat diet, malnutrition in the body during exercise, also the reduction in the total cholesterol can be explained by the fact that during exercise, increase in high density lipoprotein is accompanied by reduction in low density lipoprotein as they are the constituents making up the heart function. These findings are in agreement with that of Baydil, (2013), who reported that the change in the mean concentration of triglyceride and total cholesterol in individuals who exercised to the point of exhaustion were significant. There was also a significant decrease in the mean values of the participant myoglobin level to after exercise $(\mathrm{P}<0.05)$. This confirms the work of Ugwuja et al., 2014; who showed that exercise reduced total cholesterol and myoglobin concentration significantly. This can be attributed to the moderate intensity and short duration of the exercise (Ugwuja et al., 2014). It was also observed in this study that the pre-myoglobin concentration correlated positively with weight and HDL $(\mathrm{p}<0.005)$, whereas no correlation was found between these parameters in the post-exercise blood sample. This is in accordance with previous studies (Traynor et al., 2006; Lamb et al., 2005).

\section{Conclusion}

Based on our findings, there were significant decrease in the mean serum levels of total cholesterol, triglyceride, low density lipoprotein and myoglobin whereas, the mean serum high density lipoprotein was significantly increased in the subjects after exercise. These findings therefore, suggest that regular physical exercise has a possible positive effect on the improvement of lipid metabolism leading to a healthier cardiovascular function.

\section{Recommendation}

Based on our findings, we recommend that short term football exercise (aerobic exercise) could be used at least as an adjunct in the therapy and management of cardiovascular disease. Therefore, health education strategies should be adopted to enlighten the general public on the beneficial effects of short term aerobic exercise (football exercise).

\section{References}

1. Assman, G., Jabs, H.U., Kohnert, U., Nolte, W., Schriewer, H. (1984). LDL-cholesterol determination in blood serum following precipitation of LDL with polyvinyl sulphate. Journal of Clinical Chimical Acta; 140: 77-83. 
2. Baydil B. (2013). Serum macro-micro element response to acute maximal physical exercise. World Applied Scientific Journal;2:945-249.

3. Benedict, C.R., Shelton, B., Johnstone, D.E., Francis, G., Greenberg, B., Konstam, M., Probstfield, J.L., Yusuf, S. (1996). Prognostic significance of plasma norepinephrine in patients with asymptomatic left ventricular dysfunction. Circulation; 94:690-697.

4. Benjamin, E. J., Larson, M. G., Keyes, M. J. (2004). "Clinical correlates and heritability of flowmediated dilation in the community: the Framingham Heart Study," Circulation; 109(5): 613-619.

5. Blair, S.N. (2009). Physical inactivity: the biggest public health problem of the 21St century. British Journal of Sports Medicine; 43: 1-2.

6. Blair, S.N., Morris, J.N. (2009). Healthy hearts - and the universal benefits of being physically active: physical activity and health. Annuals of Epidemiology;19:253-256.

7. Brooks, G.A., Fahey, T.D., Baldwin, K.M., editors. Human bioenergetics and its applications. In: Exercise physiology. $4^{\text {th }}$ Ed. Mc Graw Hill; New York;2005.p.122-125.

8. Burstein, M., Scholnick, H.R., Morfin, R. (1980). Rapid method for the isolation of lipoproteins from serum by precipitation with polyanions. Scandinavian Journal of Clinical and Laboratory Investigation; 40: 583-595.

9. Charkoudian, N., Joyner, M.J., Barnes, S.A., Johnson, C.P., Eisenach, J.H., Dietz, N.M., Wallin, B.G. (2006). Relationship between muscle sympathetic nerve activity and systemic hemodynamics during nitric oxide synthase inhibition in humans. American Journal of Physiology and Heart Circulation Physiology; 291:H1378-H1383.

10. Chobanian, A.V., Bakris, G.L., Black, H.R. (2003). Seventh Report of the Joint National Committee on Prevention, Detection, Evaluation and Treatment of High Blood Pressure. Hypertension; 42(6): 1206-1252.

11. Choudhary, S., Kumar, J., Choudhary, K., Soni, N.D. (2015). Effect of Aerobic exercise on respiratory parameters in untrained and trained subjects. International Journal of Scientific Research and Management; 3(2): 2090-2096.

12. Clarkson, P., Montgomery, H. E., Mullen, M. J. (1999).“Exercise training enhances endothelial function in young men," Journal of the American College of Cardiology; 33(5): 1379-1385.

13. Davy, K.P., Miniclier, N.L., Taylor, J.A., Stevenson, E.T., Seals, D.R. (1996). Elevated heart rate variability in physically active postmenopausal women: a cardioprotective effect? American Journal of Physiology and Heart Circulation Physiology; 271:H455-H460.

14. De Vos, N., Singh, N., Ross, D., Stavrinos, T. (2005).Optimal load for increasing muscle power during explosive resistance training in older adults. The Journal of Gerontology; 60A (5): 638-647.

15. DeSouza, C.A., Shapiro, L.F., Clevenger, C.M., Dinenno, F.A., Monahan, K.D., Tanaka. H., Seals, D.R. (2000). Regular aerobic exercise prevents and restores age-related declines in endotheliumdependent vasodilation in healthy men. Circulation;102:1351-1357.

16. Durstinea, J.L., Gordona, B., Wangb, Z., Luob, X. (2013). Chronic disease and the link to physical activity. Journal of Sport and Health Science; 2(1): 3-11.

17. Gielen, S., Erbs, S., Linke, A., Möbius-Winkler, S., Schuler, G., Hambrecht, R. (2003). "Homebased versus hospital-based exercise programs in patients with coronary artery disease: effects on coronary vasomotion," American heart journal; 145(1): E3.

18. Hambrecht, R., Fiehn, E., Weigl, C. (1998). "Regular physical exercise corrects endothelial dysfunction and improves exercise capacity in patients with chronic heart failure," Circulation; 98(24): 2709-2715.

19. Hambrecht, R., Hilbrich, L., Erbs, S. (2000). "Correction of endothelial dysfunction in chronic heart failure: additional effects of exercise training and oral L-arginine supplementation," Journal of the American College of Cardiology; 35 (3)706-713.

20. Higashi, Y., Sasaki, S., Kurisu, S. (1999). "Regular aerobic exercise augments endotheliumdependent vascular relaxation in normotensive as well as hypertensive subjects: role of endotheliumderived nitric oxide," Circulation; 100(11): 1194-1202.

21. Hollmann, W., Strüder, H. K., Tagarakis, C. V., King, G. (2007). Physical activity and the elderly. European Journal of Cardiovascular Prevention and Rehabilitation; 14, 730-739. 
22. Jourkesh, M., Sadri, I., Ojagi, A., Sharanavard, A. (2011). Determination of fitness level in male and female college aged students. Archives of Applied Science Research; 3 (2): 326-333.

23. Kelley, G.A., Kelley, K.S., Vu Tran, Z. (2005). Aerobic exercise, lipids and lipoproteins in overweight and obese adults: A meta-analysis of randomized controlled trials. International Journal of Obesity and Related Metabolic Disorders; 29(8):881-893.

24. Kelley, G.A., Kelley, K.S., Vu Tran, Z. (2005). Aerobic exercise, lipids and lipoproteins in overweight and obese adults: A meta-analysis of randomized controlled trials. International Journal of Obesity Related Metabolic Disorders; 29(8):881-893.

25. Lamb, E.J., Tomson, C.R., Roderick, P.J. (2005). Estimating kidney function in adults using formulae. Annal Clinical Biochemistry; 42:321-345.

26. Lavrenčič, A., Salobir, B. G., Keber, I. (2000). "Physical training improves flow-mediated dilation in patients with the polymetabolic syndrome," Arteriosclerosis, Thrombosis, and Vascular Biology; 20(2): 551-555.

27. Levine, Robert, J. (2006). Some Recent DevelSopments in the International Guidelines on the Ethics of Research Involving Human Subjects. Annals of the New York Academy of Sciences; 918: 170-178.

28. Maiorana, A., O'Driscoll, G., Cheetham, C. (2001). "The effect of combined aerobic and resistance exercise training on vascular function in type 2 diabetes," Journal of the American College of Cardiology; 38( 3): 860-866.

29. McArdle, W.D., Katch, F.I., Katch, V.L. (2006). Essentials of exercise physiology. Lippincott Williams and Wilkins; 204.

30. McDonald, R., Keen, C. L. (1988). Iron, zinc and magnesium nutrition and athletic performance. Sports Medicine; 5:171-184.

31. Meludu, S.C., Asomugha, L., Dioka, E.C., Osuji, C., Agbasi, A.C., Ifeanyichukwu, M., Oluboyo, O.A. (2005). Exercise Performance In Relation To Glucose Drink and Their Effect on Some Biochemical Parameters. Nigerian Journal of Physiological Sciences; 20 (1-2): 43-47.

32. Nevell, M.E., Boobies, L.H., Brook, S., Williams, C. (1989). Effects of training on muscle metabolism drug treadmill sprinting. Journal of Applied Physiology; 67:2376-2382.

33. O'Connor, D., Crowe, M., Spinks, W. (2006). Effects of static stretching on leg power during cycling. Turin ; 46(1): 52-56.

34. O'Keefe, J.H., Vogel, R., Lavie, C.J., Cordain, L. (2010). Organic fitness: Physical activity consistent with our hunter-gatherer heritage. The Physician and Sports Medicine; 4(38): 1-8.

35. Penedo, F.J., Dahn, J.R. (2005). Exercise and well-being: a review of mental and physical health benefits associated with physical activity. Curr Opin Psychiatry; 18(2): 189-193.

36. Plowman, S.A., Smith, D.L. (2007). Exercise Physiology for Health, Fitness, and Performance. Lippincott Williams and Wilkins; 61.

37. Rayssiguier, Y., Guezennecc, C. Y., Durlach, J. (1990). New experimental and clinical data on the relationship between magnesium and sport. Magnesium Research; 3:93-102.

38. Roeschlau, P., Bernt, E., Gruber, J.W. (1974). Enzymatic procedure for cholesterol determination. Journal of Clinical Chemistry and Clinical Biochemistry; 12:403.

39. Saranchak, H. J., Bernstein, S. H. (1974). A new diagnostic test for acute myocardial infarction: The detection of myoglobinuria by radioimmunodiffusion assay. Journal of American Medical Association; 228:1251.

40. Sattelmair, J. R., Pertman, J. H., Forman, D. E. (2009). Effects of physical activity on cardiovascular and noncardiovascular outcomes in older adults. Clinical Geriatric Medicine; 25: 677-702.

41. Snežana, Bošnjak. (2001). the declaration of Helsinki: The cornerstone of research ethics. Archive of Oncology; 9 (3): 179-84.

42. Third Report of the National Cholesterol Education Program (NCEP) (2002). "Expert Panel on Detection, Evaluation, and Treatment of High Blood Cholesterol in Adults (Adult Treatment Panel III) final report," Circulation; 106: 3143-3121.

43. Tietz, N.W., Saunders, W.B. and Co. (1990). Clinical guide to Laboratory Tests. $3^{\text {rd }}$ Edition; 91.

44. Traynor, J., Mactier, R., Geddes, C.C. (2006). How to measure renal function in clinical practice. British Medical Journal;333: 733-737. 
45. Ugwuja, S.E., Obeagu, E.I., Ochei, K.C. (2014). Effect of physical exercises on serum electrolyte. Journal of Dental and Medical Science; 13:118-121.

46. Vona, M., Rossi, A., Capodaglio, P. (2004). "Impact of physical training and detraining on endothelium-dependent vasodilation in patients with recent acute myocardial infarction," American Heart Journal; 147 (6):1039-1046.

47. Wilmore, J., Knuttgen, H. (2003). Aerobic exercise and endurance improving fitness for health benefits. The physician and sports medicine; 31(5):45.

48. Wilmore, J., Knuttgen, H. (2003). Aerobic exercise and endurance improving fitness for health benefits. The physician and sports medicine; 31(5):45.

49. Wilt, T.J., Bloomfield, H.E., MacDonald, R., Nelson, D., Rutks, I., Ho, M., Larsen, G., McCall, A., Pineros, S., Sales, A. (2004). Effectiveness of statin therapy in adults with coronary heart disease. Archive of International Medicine;164:1427-1436. 